\title{
Uveljavljanje slovenščine kot poslovnega jezika v času Marije Terezije in Jožefa II.: patenti v slovenskem jeziku
}

\begin{abstract}
Der Beitrag befasst sich mit dem Gebrauch der slowenischen Sprache in rechtlichen und normativen Urkunden ab dem 18. Jahrhundert. Seit dem ersten heute bekannten Patent, erschienen 1749 in slowenischer Übersetzung in Kärnten, ist die Zahl der Dokumente langsam, aber stetig gestiegen. Mit den kaiserlichen Patenten erhielt die slowenische Sprache eine unmittelbare amtliche Bedeutung, die Patente wiederum förderten die Vereinheitlichung der Sprache. Da eine gründliche historische und sprachliche Analyse der slowenischen Patente noch aussteht, soll mit dem Beitrag das Interesse für diese Thematik an den Slawistikinstituten der österreichischen Universitäten geweckt werden.
\end{abstract}

Od druge polovice 18. stoletja lahko spremljamo kontinuirano uveljavljanje slovenščine $\mathrm{v}$ javnem življenju. V slovenskem zgodovinopisju in literarni zgodovini je to obdobje označeno kot čas narodnega preporoda. V Enciklopediji Slovenije je narodno prerodno gibanje označeno kot ,zgodnje začetno obdobje modernega narodnega gibanja“, ki se pojavlja pri narodih, ki še nimajo višje kulture v lastnem jeziku. Nadaljuje, da so bila ta gibanja pojav zadnjih desetletij 18. in druge polovice 19. stoletja, da so bila sprva omejena na redke izobražence in kulturne ustvarjalce ter da so težila k uveljavitvi živega, „ljudskega“ jezika v šolah, književnosti in znanosti, se zato posvečala raziskovanju ljudske govorice, zgodovine in običajev ter poskušala doseči spremembo ,jezikovno-kulturne prakse“ na svojem narodnem ozemlju s književnim in kulturnim delom. Kot začetek slovenskega narodnega preroda je označen izid Kraynske gramatike Marka Pohlina leta 1768:

Prvi pomembnejši vrh je doseglo s Zoisovim krogom in Antonom Tomažem Linhartom, ki je gibanju dal z delom Versuch einer Geschichte von Krain und den übrigen Ländern der südlichen Slaven Oesterreichs I-II $(1788,1791)$ znanstveno podlago. (Enciklopedija Slovenije 1993: 313)

Prva pobuda za delo narodnih buditeljev pa naj bi bil odpor proti stališčem, po katerih naj bi se slovenski jezik ,zaradi majhne koristnosti pozabil in odpravil iz dežele“, saj ga „,v javnem življenju uporablja samo nižje ljudstvo“, ter strah, „da bi 
germanizacija absolutistične države dosegla pomembne uspehe“ (Grafenauer 1974: 126, 127).

Ne glede na to, kakšne so bile dejanske pobude za kulturno delo slovenskih prebuditeljev, je nedvomno dejstvo, da njihovo delo sovpada s časom uveljavljanja slovenščine kot jezika prava, in to z objavami patentov v slovenščini, hkrati pa se je začela uveljavljati slovenščina tudi na drugih področjih državne uprave.

Nedvomno se je z ukinitvijo jezuitskega reda 1773 in z njim jezuitskih kolegijev, kjer je bil učni jezik latinščina, in z ustanovitvijo licejev, kjer je postala učni jezik nemščina, vloga nemščine v državi silno povečala, medtem ko slovenščina ni imela enakih možnosti.

Vsekakor pa ne gre zanemariti dejstva, da se je slovenščina začela uveljavljati v javnem življenju, poleg cerkve tudi v šolstvu ter v državni upravi, ter da je osrednja državna oblast z nekaterimi svojimi potezami veljavi slovenščine koristila. Od srede 18. stoletja je objavljala pravne in upravne akte, kot so patenti, in druge normativne akte v tiskani obliki.

Ljudski jeziki v monarhiji so v drugi polovici 18. stoletja postajali vse pomembnejši. Prvič v zgodovini so šteli jezik kot enega od kriterijev pri organizaciji cerkvene uprave. Cesarjev komisar za reorganizacijo škofijskih meja v Notranji Avstriji državni grof Jožef Franc Anton Auersperg je leta 1783 predlagal razmejitev med lavantinsko škofijo, preneseno na Spodnjo Štajersko s sedežem v Mariboru, Celju ali Ptuju, po slovensko-nemški jezikovni meji (glej: Rajšp 1999).

Živi jeziki so prodirali tudi na druga državna področja, kot so bile na primer vojaške zadeve. Na prvi specialki ozemelj monarhije „Josephinische Landesaufnahme“ so zapisovali toponime tudi v ljudskih, nenemških jezikih. Zapisovanje imen v takrat znanih jezikih je temeljilo na odredbi cesarja Jožefa II. iz leta 1773 kartografu oficirju Jeneyju, ki je vodil kartiranje tudi na slovenskem jezikovnem območju, da mora zapisati vsa imena hribov, dolin in voda ,in der Landessprache gebräuchlichen Namen " (Rajšp 2000: XXV).

To navodilo so vojaški kartografi upoštevali v veliki meri tudi na slovenskem jezikovnem območju. Številne toponime so poleg nemščine in italijanščine (na Primorskem) zapisali tudi v slovenskem jeziku (Pettau - Obtuy /Ptuj/), na področju Prekmurja pa nekatere v vseh treh jezikih, ki so bili tam v rabi: madžarskem, slovenskem in nemškem (Mura Szombat - Olsnitz - Sobota /Murska Sobota/; Csernelocz Czernerowcze /Černelavci/). Iz celote je jasno razvidna prevladujoča vloga nemščine. Opisi so v nemščini. V Notranji Avstriji prevladujejo nemške oblike krajevnih imen; v ogrskem delu, to je v Prekmurju, prevladujejo sicer madžarska imena, opisi pa so prav tako v nemščini, vendar so zapisi slovenskih imen na uradni državni karti kljub temu neprecenljivega pomena.

V okviru simpozija „Slovenistika v Avstriji“ je morda prav, da opozorimo tudi na uveljavljanje slovenskega jezika $\mathrm{v}$ drugi polovici 18. stoletja na državni ravni, pri čemer je imel Dunaj, kot glavno mesto države, pomembno vlogo. 
$\mathrm{Na}$ vprašanje, kakšni in kateri razlogi so vodili osrednje oblasti, da so začele upoštevati tudi manjše jezike v državi in niso vztrajale le pri enem državnem jeziku, je možnih več odgovorov. Razsvetljeni absolutizem se je pri reformah, za katere je bilo potrebno širše razumevanje zahtevanega, prav tako pa tudi višja izobrazba prebivalstva, začel posluževati splošno razumljivih ljudskih jezikov, med katerimi je prišla tako do večje veljave tudi slovenščina. Nedvomno gre za pomemben korak pri formiranju narodov nekdanje skupne države, ki imajo v večini primerov danes tudi lastno državo; s tem je bil usmerjen razvoj v drugo smer, kot če bi prevladala ideja centralizma $\mathrm{z}$ enim, v našem primeru gotovo nemškim jezikom.

Vprašanje o rabi ljudskih jezikov v državni upravi je postalo aktualno šele v času absolutizma v habsburških deželah, ko je osrednja državna uprava direktno posegala na različna področja, ki so zadela najnižje sloje prebivalcev, ki nemščine niso znali. $\mathrm{V}$ veliko večji meri kot dotlej so prihajale zahteve, ki so direktno zadevale podložnike, iz centra - Dunaja. Do tega časa so to vlogo opravljale dežele s svojo stanovsko upravo in privilegiji. Absolutistične reforme so zadevale najširše plasti prebivalstva: v deželah s slovenskim prebivalstvom dotedanje deželne oblasti in upravo, ki je bila po večini nemško govoreča, na Goriškem in v Trstu italijansko, pa tudi večinsko slovensko govoreče prebivalstvo. Slednjim jih je bilo razumno približati tudi v njim razumljivem - slovenskem jeziku.

Slovenščina je dobila javno veljavo v protestantski cerkvi v 16. stoletju, ko je Primož Trubar izdajal prve slovenske knjige. Nikakor pa se takrat še ni dvignila na poslovno raven in na raven korespondence, niti med tistimi, ki so sicer podpirali slovenske knjige in med seboj nedvomno občevali v slovenščini. Trubarjeva korespondenca je nemška. Vdova slovenskega protestantskega učitelja v Škocjanu pri Turjaku piše prošnje za finančno podporo po moževi smrti v nemškem jeziku (Rajšp 1992: 65-67).

Bistveno so se razmere glede javne rabe slovenščine spremenile v 18. stoletju, ko je začela naraščati raba živih jezikov v upravi in zakonodaji. To se sicer ni zgodilo naenkrat in v celoti, vendar se vzpon ni več zaustavil.

Na Kranjskem je viden tak razvoj v zvezi z gradnjo cest v času cesarja Karla VI. Začeli so ponovno uvajati delovno tlako za gradnjo cest. Pri tem so se sklicevali na odredbe iz preteklosti, ki so bile vsaj med podložniki že pozabljene. Ceste so imeli razne lastnike, ki so jih običajno vzdrževali vsak po svoje. Z zahtevo po gradnji komercialnih cest se je to spremenilo. Gradnjo cest je vzela v svoje roke država, ki pa za gradnjo ni imela denarja, temveč je kot zastonjsko delovno silo uporabljala podložnike. Zadeva ni bila enostavna, saj so se podložniki zahtevi izogibali, očitno pa ji velikokrat niso bili naklonjeni niti zemljiški gospodje, ki so uvideli, da se tlačna obveznost podložnikov povečuje, veliko potrebo po tlaki pa so imeli tudi sami (na primer pri gradnji ali obnovah gradov). Najbolj vidno je bilo to pri Auerspergih v Kočevju, ki so celo opravičevali odsotnost podložnikov pri gradnji cest, češ da jih ni doma, da so slabe letine in da beračijo po Hrvaškem. 
Oblasti so sicer nastopale s kaznimi, vendar to na splošno ni bilo uspešno. Podložniki so se namreč redno izgovarjali, da za ukaz niso vedeli, ker ga niso razumeli. Tako so oblasti ukazale župnikom, da jim ukaze tolmačijo v domačem, njim razumljivem - v tem primeru slovenskem jeziku. Ker tudi to očitno ni bilo učinkovito župniki namreč zahtev po tlaki niso vedno dovolj razumljivo tolmačili - je prišla zahteva, da naj ukaze berejo v slovenščini. To pa je nedvomno odprlo pot slovenščini kot poslovnemu jeziku.

Doslej najstarejši znani objavljeni patent $\mathrm{v}$ slovenskem jeziku nosi datum 26. maj 1749 na Dunaju, obravnaval pa je dezerterstvo (objava v: Domej 1986: 464). Drugi patent iz leta 1752, ki je bil objavljen na Dunaju in v Celovcu (,Danu v' mejsti Dunay potler v' Celouci na 8. dan Mesza Maja 1752“), pa se je nanašal na gospodarsko področje, in sicer na uvajanje dunajskih votlih mer in uteži na Koroškem (,v' koroshki desheli“) (Domej 1986: 467).

2. marca 1754 je izšel za Koroško patent, ki je urejal lovske zadeve:

Mi Maria Theresia ... Damo s' Letem usim, inu usakimo nashiga poerbaniga Koroskiga Herzogthuma ... Danu v' Celouzi ta II. Dan tiga Messiza Martia v' Letu 1754. (Domej 1986: 470)

Meseca maja istega leta je izšel patent, ki je veljal v slovenski zgodovinski literaturi kot najstarejši (Reisp 2001: 114), izdala ga je Marija Terezija „,v' Dunaij na 10. dan Mesza Maja 1754“ (Domej 1986: 476). Objavila ga je reprezentanca in komora koroške vojvodine $\mathrm{v}$ zvezi z odpravo nekaterih praznikov, kakor jih je predpisal papež Benedikt XIV. Za Koroško je bil patent preveden v slovenščino, medtem ko so v Ljubljani znani le nemški izvodi tega patenta.

Najstarejši slovenski patent za Kranjsko, ki ga je izdala Marija Terezija, pa je izšel 6. julija 1758 in bil posvečen socialnemu skrbstvu za osebe vojaškega stanu. Objavili so ga istočasno v nemškem originalu ter v slovenskem in italijanskem prevodu. Naslednji znani slovenski razglas, ki ga je izdala cesarica Marija Terezija 23. marca 1766 na Dunaju, pa je red za čolnarje in vožnjo po Savi, ki je veljal za Kranjsko in Štajersko:

My Maria Theresia [...] Napovemo vsim, slasti pa nashim suestim Podloshnim u Staierski, inu Krainski Deshelli, katiri srauin Save Greshine, Grunte imajo, inu stanujejo, nasho Gnado inu vse dobru. Inu vam na snaine damo, de smo mi savolo Pogmirejna te Kupzhie med nashim Nemshkim, inu Ogerskim Deshellam sa Potrebnu sposnalli, to Voshno na Savi pogmirat, $u$ eno prauo Versto inu stan postauit. (Patenti)

Patent v nemškem in slovenskem jeziku za Štajersko je bil objavljen 5. decembra 1778 , nanašal pa se je na tlako:

Mi Maria Theresia [...] Zapovemo vsim, inu vsakim Nashim podloshnim Gosposkam, tudi Nashim Svestim deshellskim Glavarjam, Oblastnikam, Hmetam, Kozherjam, inu Podloshnikam lete Nashe Steüerske Deshelle [...]. (Arhiv Republike Slovenije, Normalije, Š 4)

Število slovenskih razglasov se je v naslednjih letih večalo. V slovenščino sicer še zdaleč niso bili prevedeni vsi patenti: za drugo polovico 18. stoletja jih poznamo 
nekaj nad 20, različno je bilo tudi od dežele do dežele, v prednosti je bila Koroška, sledila ji je Kranjska, prevajali pa so jih tudi na Štajerskem, vendar ne gre zanemarjati pomena, ki ga je s temi patenti pridobila slovenščina, saj si je pridobila veljavo od države priznanega poslovnega jezika.

Uveljavljanje domačega, slovenskega jezika pri uradnem poslovanju pa je predstavljalo kompleksen problem. Potrebno je bilo namreč tudi uradništvo, ki je znalo slovenščino. Tako je na primer predsednik reprezentance in komore na Kranjskem leta 1750 dvornim oblastem predlagal povišanje uradniških plač z utemeljitvijo, da je uradnike v Ljubljani težje dobiti, saj morajo poleg nemščine in latinščine znati še italijanščino in pogosto še deželni jezik, to je slovenščino (Valenčič 1977: 330).

Oviro pri izdajanju patentov v slovenskem jeziku je večkrat predstavljalo pomanjkanje usposobljenih prevajalcev, in ne morda nenaklonjenost oblasti na Dunaju. To se je lepo pokazalo pri kranjskem gozdnem redu leta 1771, ki je poleg gozdnopolicijskih predpisov vseboval tudi poljuden pouk o gospodarjenju z gozdovi. Dunajska vlada je ukazala, naj ga deželno glavarstvo objavi v nemškem in slovenskem jeziku. Vendar niso našli prevajalca, ki bi red prevedel. V slovenščini je bil objavljen šele leta 1824 (Valenčič 1977: 333).

Na Kranjskem so objavljali patente ne le v slovenščini, temveč tudi italijanščini in hrvaščini. Takšen je bil patent Marije Terezije iz leta 1770 (italijanski izvod navaja letnico 1771), objavljen v Ljubljani, ki pa se je nanašal v prvi vrsti na hrvaško jezikovno področje: obravnaval je vdore preko turške meje. Da mora biti patent objavljen v „običajnih treh jezikih“, je bila zahteva patenta (Suyer).

Leta 1781 je cesar Jožef II. izdal dva patenta o tem, kako naj podložniki vlagajo pritožbe proti svojim gosposkam in kako morajo gosposke ravnati pri kaznovanju podložnikov. Oba patenta sta bila v nemščini, italijanščini in slovenščini (Suyer).

Leta 1790 je bil v italijanščini, nemščini in slovenščini na Goriškem objavljen še razglas o novih davkih, leta 1795 pa je deželno glavarstvo na Kranjskem objavilo razglas o prekem sodu pri ravnanju z razbojniki, v nemško-slovensko-italijanski izdaji (Suyer).

Zelo pa se je povečalo število patentov v letih 1803 do 1809 , ko jih je izšlo za Kranjsko in Goriško (v slovenskem in italijanskem jeziku) vsaj 15.

Za sorazmerno majhno število patentov v slovenskem jeziku v drugi polovici 18. stoletja je bilo nedvomno krivo dejstvo, da je primanjkovalo ljudi, ki bi znali prevajati strokovno terminologijo. V Ljubljani se je deželno glavarstvo obračalo na rektorja jezuitskega kolegija Inocenca Tauffererja. Vendar je Taufferer le iskal prevajalce, saj ni bil v kolegiju nihče dovolj podkovan za prevajanje v slovenščini. Pred letom 1773 je, kot sam piše, posredoval prevod več dvornih resolucij. Prav tako izvemo, da sta mu prevajala dva duhovnika. Vendar že prevod „Poduka za babice = Hebammenunterricht”, za kar je prosilo glavarstvo, ni našel prevajalca.

Dvorna komora na Dunaju je leta 1775 naročila deželnemu glavarstvu v Ljubljani, naj izda šolski red, kar se dotlej še ni zgodilo. V slovenščino naj bi red prevedel 
ravnatelj normalke v Ljubljani Blaž Kumerdej (1738-1805), vendar se to takrat ni zgodilo. Kot prevajalci patentov se omenjajo Jurij Japelj, Anton Tomaž Linhart (Valenčič 1977: 334) in Marko Pohlin (Reisp 1967: 91).

Patenti so nedvomno pomembni dokumenti o razvoju slovenske pravne in upravne terminologije. Vendar doslej temeljiteje še niso bili obdelani. Vseh patentov v slovenščini po posameznih deželah niti še nimamo sistematično zbranih. Ker gre za nemško-slovenska besedila, bi lahko bili patenti primerna snov za različne naloge študentov slovenistike v Avstriji, ki znajo oba jezika. Zato zaključujem s pozivom, da se patenti vključijo na seznam magistrskih nalog.

\section{Literatura}

Domej 1986: T. R. Domej, Die Slowenen in Kärnten und ihre Sprache mit besonderer Berücksichtigung des Zeitalters von 1740 bis 1848, disertacija, Wien

Enciklopedija Slovenije 1993: Enciklopedija Slovenije 7, Ljubljana

Grafenauer 1974: $\quad$ B. Grafenauer, Zgodovina slovenskega naroda, 5. zv., Ljubljana

Patenti:

Rajšp 1992:

Patenti, zbirka, Inštitut za slovenski jezik Frana Ramovša ZRC SAZU

Rajšp 1999:

V. Rajšp, Protireformacija na Kranjskem na primeru župnije Škocjan pri Turjaku, Bogoslovni vestnik 52/1-2, 65-71

Rajšp 1999:

V. Rajšp, Karte ob novi razmejitvi škofij na področju Notranje Avstrije v času cesarja Jožefa II, v: Vilfanov zbornik. Pravo, zgodovina, narod / Recht, Geschichte, Nation, ur. Vincenc Rajšp, Ernst Bruckmüller, Ljubljana, 341-362

Rajšp 2000:

V. Rajšp, Slovenija na vojaškem zemljevidu / Die Josephinische Landesaufnahme 1763-1787, 6. zv., Ljubljana

Reisp 1967: $\quad$ B. Reisp, O najstarejših tiskanih uradnih razglasih v slovenščini. Kro-

Reisp 2001:

Suyer: nika, časopis za slovensko krajevno zgodovino 15/2, 91-94

B. Reisp, Redki stari tiski, Ljubljana

V. Suyer, Starejši slovenski prevodi patentov, rokopis, Inštitut za Slovenski jezik Frana Ramovša ZRC SAZU

Valenčič 1977: $\quad$ V. Valenčič, Slovenščina v uradih, Zgodovinski časopis 31/3, 329-360

Vincenc Rajšp

Slovenski znanstveni inštitut Dunaj

Slowenisches Wissenschaftsinstitut Wien

Seilerstätte 2, A-1090 Wien/Dunaj

vincenc.rajsp@szi-dunaj.at 